\title{
ESTUDOS DE IMPACTO AMBIENTAL E PLANOS DE RECUPERAÇÃO EM MINERAÇÃO: EXIGÊNCIA BUROCRÁTICA OU DEFESA DO MEIO AMBIENTE?
}

\author{
A.B.Macedo ${ }^{1}$
}

A partir da formulação da exigência legal de estudos de impacto ambiental (EIA/RIMA) pela resolução n $1 / 86$ do Conselho Nacional do Meio Ambiente (CONAMA), centenas de relatórios referentes a minerações foram entregues aos órgáos de controle ambiental em todo o Brasil. Em São Paulo, de 142 relatórios submetidos à Secretária Estadual do Meio Ambiente, 80 eram dedicados a empreeendimentos de mineração.

Grande parte destes estudos foram recusados por falta de mínimas qualidades técnicas. Todos necessitaram de complementação antes que pudessem ser julgados. Mesmo entre os aprovados, faltam dados que seriam necessários para completa avaliação da viabilidade da lavra e das soluções propostas para controle da poluição e recuperação das áreas afetadas.

Desde aquela época a legislação e as práticas administrativas tornaram-se mais rígidas, sendo a obrigatoriedade da recuperação das áreas afetadas pela mineração fixada na própria Constituiçăo.

A partir do decreto 97.632/89 uma avalanche de planos de recuperação foi entregue aos órgãos ambientais, tanto por parte de minerações organizadas quanto de garimpos. Observaçöes preliminares revelam também neste caso grandes problemas de elaboraçāo.

As principais razões para a ocorrência de problemas nestes estudos e planos são: a) a falta de dados básicos acessíveis: os levantamentos básicos cobrem apenas áreas reduzidas do território nacional, na maioria dos casos em escala inferior à necessária para os estudos. O desmantelamento do serviço páblico ora em curso só agrava o problema. Mesmo

\footnotetext{
Tepartamento de Geologia Econômica e Geofisica Aplicada, Instituto de Geociências/USP, São Paulo.
} 
quando existentes, os dados são pouco acessíveis, não sendo publicados e em alguns casos têm sua consulta restrita como se fossem de propriedade particular; b) a ausência de normas claras para a elaboração dos estudos: a Resolução é muito geral, e poucos Estados (como Sergipe e São Paulo) especificaram claramente o que deveria ser levantado. Em alguns casos as exigências variam na prática para mineraçōes de mesmo porte, com menores exigências para garimpos que para minerações estabelecidas pelo regime de concessão; c) a exigência indiscriminada de estudos completos para mineraçóes de tipos e portes muito diferentes: a lei não discrimina entre tipos e portes de minerações, levando à banalização dos estudos; d) a concorrência de preço entre as empresas executoras, aceitando contratos por preços inferiores ao custo da obtenção dos dados: assim, são aproveitados dados secundários pouco confiáveis e os projetos são executados por pessoal pouco habilitado; e) a mentalidade dos mineradores, habituados a enviar ao DNPM documentos apenas para cumprimento de formalidades, sem fundamentação técnica: o DNPM em muitos casos aprovou pedidos, planos e relatórios que uma simples verificação reprovaria. Esta indulgência leva os mineradores a tentar a mesma prática com os órgãos de meio ambiente. O problema pode então se repetir, pois os estudos são em muitos casos julgados segundo o arbítrio dos técnicos e políticos encarregados, faltando transparência e democracia no processo.

Para que os estudos de impacto ambiental e planos de recuperação de áreas degradadas pela mineração sejam realmente úteis para a defesa do meio ambiente é necessário que: a) sejam fomentados os levantamentos básicos, por parte do órgáos estatais competentes, nas áreas de topografia, geologia, geomorfologia, hidrologia superficial e hidrogeologia, fauna, flora, etc. É necessário que as instituições que executam os levantamentos tenham pessoal em número e qualidade adequados e que sejam eliminadas as duplicações comuns no passado; b) que estes levantamentos se tornem disponíveis aos que elaboram os estudos locais, preferivelmente na forma de bancos de dados acessáveis por teleprocessamento, garantindo-se a publicação em edições compatíveis com a demanda; c) que sejam encorajados estudos conjuntos de impacto ambiental por mineraçōes com áreas de influência coincidentes ou muito próximas: assim os dados de diagnóstico apenas necessitam ser levantados uma vez, o que pode ser então feito com o devido cuidado a custos reduzidos para cada minerador envolvido; d) que as exigências para os estudos sejam fixadas de forma clara e detalhada, de preferência a partir de estudos técnicos elaborados por grupos que incluam representantes dos órgãos governamentais, universidades e particulares: o mínimo que um empreendedor pode exigir do Estado é que as normas sejam claras, o que não acontece quando cada órgão cria suas instruções sem ouvir os outros interessados. Devem ser encorajadas iniciativas como as do 
Projeto Diretrizes para a Mineração de Areia na Região Metropolitana de São Paulo, bem como as do CREA, ABNT e CONSEMA de São Paulo, que tentam criar condições para estudos e normas elaboradas conjuntamente; f) que as exigências sejam graduadas de acordo com o porte e potencial poluidor das minerações: a maioria das mineraçōes, por terem pequeno porte ou potencial poluidor, poderiam ser licenciadas a partir de um Memorial de Caracterização e Plano de Recuperação simplificado, como foi tentado no Projeto Guarapiranga, reservando-se o EIA completo apenas para as de grande potencial poluidor; g) que seja generalizada a prática de discussão dos estudos e planos através de conselhos com ampla representação da sociedade, como o CONSEMA de São Paulo: este Conselho inclui representantes dos órgãos do governo estadual, universidades, associações de empresários e trabalhadores e grupos ambientalistas, tendo poder deliberativo sobre a aprovação de EIAs no Estado. Mesmo que o processo seja moroso e caro, é a única maneira de adaptar as recomendações técnicas à realidade prática; h) que seja feita uma fiscalização rigorosa sobre a elaboração e aplicação de estudos e planos, por funcionários com a devida formação técnica: estes devem ter condições materiais e apoio político suficientes para o exercício digno de suas funções. Para sua formação, bem como a dos profissionais encarregados da elaboração, devem colaborar os órgãos do Meio Ambiente, as Universidades e as empresas. Assim, não só os planos serão efetivamente executados, mas os dados neles incluídos poderão ser aproveitados para estudos de síntese e planejamento. 